British paediatrics

\title{
Future development of the public health function and community medicine
}

The Department of Health and Social Security (DHSS) has set up a committee of inquiry into the future development of the public health function and community medicine. In its evidence to this committee the British Paediatric Association (BPA) emphasises the role of the Association and its members in the field of public health and reaffirms its commitment to an integrated comprehensive child health service.

The BPA considers that paediatrics and community medicine must work together in partnership on the administrative aspects of a comprehensive child health service, with consultant paediatricians providing the clinical leadership. Paediatricians working primarily in the community should undertake some administrative duties in addition to their clinical functions. Paediatric advice should be sought on certain aspects of planning, such as the use of hospital resources and the most appropriate types of service for the handicapped child.

Splitting the child health service into hospital and community divisions is inimical to the development of an effective comprehensive service. Preventive and curative services should therefore be integrated and health districts should have a single paediatric and child health division to which all specialist medical personnel in the child health service should belong. At primary care level general practitioners and clinical medical officers must increasingly come together. The criteria on which the allocations of resources is based should include outpatient and day care services (incorporating those for children with physical and mental handicap) and the number of inpatient beds for children and their occupancy.

Postgraduate training for community child health medical staff is essential at both primary and secondary care levels if the child health service is to be improved. This implies support for academic departments of child health, which are best able to determine training requirements and provide the training.

The main recommendations of the BPA are:

(1) Integration of the child health service should be promoted more actively.

(2) There should be at least one consultant paediatrician in community child health per district, building up to two or three in due course.

(3) Facilities should be provided for improving the postgraduate training of child health doctors.

(4) The allocation of financial resources for the child health services should be based on more appropriate criteria and the resources should be made available in a single budget rather than by funding hospital and community services separately.

A D M JACKSON 